\title{
Atuações das autoridades monetárias brasileiras diante da crise financeira internacional
}

\author{
Luciano Luiz Manarin D’Agostini*
}

\begin{abstract}
RESUMO - Diante do cenário de crise financeira internacional, este estudo mostra: (i) as ações emergenciais tomadas pelas autoridades monetárias no Brasil, via instrumentos de controle monetário, observados nos meses de setembro a novembro, para regularizar a liquidez em moeda estrangeira e em reais no mercado; e (ii) os efeitos que os instrumentos de controle monetário e as novas medidas podem causar em variáveis macroeconômicas como juros, inflação e câmbio.
\end{abstract}

Palavras-chave: Política monetária. Instrumentos de controle monetário. Crise de liquidez.

\section{INTRODUÇÃO}

Os agravamentos das crises nos Estados Unidos e Europa, em meados de agosto, em sua primeira fase, causaram impactos pouco perceptíveis na economia brasileira. $\mathrm{Na}$ segunda fase, após a falência do Lehman Brothers, em setembro, impactos imediatos no crédito da economia brasileira foram observados.

$\mathrm{Na}$ primeira fase existia maior preocupação do governo brasileiro com o choque de commodities e com a inflação ${ }^{28}$. Nesta, observou-se repentina depreciação do real perante o dólar, retração do crédito internacional, elevação do custo financeiro para países emergentes, redução do saldo em conta corrente devido ao preço do petróleo e aumento das remessas de lucros para o exterior.

$\mathrm{Na}$ segunda fase, revelaram-se os grandes prejuízos contábeis no setor financeiro mundial, até então ocultos e bem acima das previsões do mercado financeiro. Isto fez com que os preços dos ativos financeiros de renda variável negociados nas bolsas de valores do mundo tivessem forte queda. A crise de solvência de grandes instituições financeiras como Fannie Mae, Freddie Mac, a concordata do Lehman Brothers nos Estados Unidos, os bancos Fortis e Dexia, na Europa, fizeram a crise de solvência se transformar numa crise de confiança, em especial, entre os bancos. O travamento do crédito mundial foi imediato, os

\footnotetext{
* Economista, Doutorando em Desenvolvimento Econômico da Universidade Federal do Paraná. Endereço eletrônico: lucianodagostini@hotmail.com.

${ }^{28}$ Ver MANTEGA (2008a, 2008b), MEIRELLES (2008a, 2008b) e BANCO CENTRAL DO BRASIL (2008a, 2008b).
} 
preços das commodities caiu abruptamente no mercado internacional e o dólar se apreciou perante as principais moedas internacionais, com exceção do yen japonês.

No Brasil, os impactos imediatos foram sentidos pela interrupção das linhas de financiamentos externas, empoçamento do crédito doméstico pelos bancos comerciais, perdas patrimoniais de agentes privados no mercado acionário e de derivativos, de detentores de empréstimos em dólares e desmonte do carry trade com grandes fugas de capitais de estrangeiros da bolsa de valores.

Segundo o Banco Central do Brasil (BCB), a linha de adiantamentos de contratos de câmbio (ACCs) caiu drasticamente na segunda fase do agravamento da crise financeira internacional. Em setembro, a média dos ACCs por dia útil foi de US\$238,8 milhões, enquanto que nos primeiros dez dias úteis de outubro, este número caiu para US\$116,2 milhões, uma queda de 51,34\%.

Diante deste cenário, a resposta do governo brasileiro para a restrição do crédito foi imediata. $\mathrm{O}$ BCB e o Ministério da Fazenda tomaram diversas medidas de política monetária e fiscal para aumentar a liquidez em moeda estrangeira e em moeda nacional. Utilização de swaps cambiais, maior ação dos bancos públicos, aumento dos recursos do BNDES, especialmente das linhas pré-embarque, utilização do depósito compulsório e reservas internacionais, antecipação dos desembolsos para a safra agrícola 2008/09, novas linhas de capital de giro para construção civil e setor automobilístico. Estas medidas tomadas pelas autoridades são detalhadas a seguir.

\section{MEDIDAS PARA AUMENTAR A LIQUIDEZ EM MOEDA ESTRANGEIRA}

Cronologicamente, as medidas que o $\mathrm{BCB}$ tomou para aumentar a liquidez em moeda estrangeira foram: (i) em 18 de setembro, implementou leilões de linhas em dólares spot com compromisso de recompra futura; (ii) de 06 de outubro em diante observa-se constantes swap cambiais DIxCâmbio; (iii) no dia 06 de outubro a medida provisória 442 autoriza o $\mathrm{BCB}$ a fazer empréstimos em moeda estrangeira com garantias; (iv) em 08 de outubro o BCB volta a fazer operações de venda em dólares spot sem compromisso de recompra futura; (v) em 13 de outubro, o BCB divulgou a liberação de compulsório sobre captações por meio de empresas de leasing aos bancos que entrarem nos leilões de linhas externas; (vi) em 16 de outubro foram executados leilões de empréstimos em moeda estrangeira com garantias para o financiamento do comércio exterior em global bonds. 
Para prover a liquidez em dólares, até o começo de novembro houve a injeção de US\$ 14 bilhões. Deste total, US\$ 5,1 bilhões sob forma de venda à vista. Para prover a liquidez em dólares, direcionando recursos para o financiamento das exportações, somou-se US $\$ 5,8$ bilhões em leilões de recompra; US $\$ 1,6$ bilhão com garantias em global bonds e US $\$ 1,5$ bilhão com garantias em ACC e ACE (Adiantamento de Contratos Cambiais/ Entregues).

As medidas para reduzir a volatilidade do mercado cambial já somam, até o começo de novembro, US $\$ 27$ bilhões. Destes, US $\$ 25,5$ bilhões em vendas de swap cambial e US $\$ 1,5$ bilhões em não rolagem de swap cambial reverso.

Do total de US\$ 40 bilhões, a única medida que afeta as reservas internacionais são as vendas de dólares à vista, que representaram US $\$ 5,1$ bilhões ${ }^{29}$.

Além das ações internas supracitadas, ações externas para aumentar a liquidez em moeda estrangeira foram tomadas. O BCB e o Federal Reserve estabeleceram linha de swap de moedas de US\$ 30 bilhões até 30 de abril de 2009. Esta linha será utilizada para incrementar os fundos disponíveis para provisão de liquidez em dólares pelo $\mathrm{BCB}^{30}$.

\section{MEDIDAS PARA AUMENTAR A LIQUIDEZ EM MOEDA NACIONAL}

As medidas do BCB no mercado interbancário se concentraram nos instrumentos de depósito compulsório e operações de redesconto. Cronologicamente, as medidas que o BCB tomou para aumentar a liquidez em moeda nacional foram: (i) em 24 de setembro postergouse o cronograma de recolhimento compulsório sobre depósitos interfinanceiros captados; (ii) em 24 de setembro ampliou-se o valor dedutível de recolhimento compulsório; (iii) em 2 de outubro houve alteração do regime de compulsórios visando estimular compra de carteiras de crédito, (iv) pela medida provisória 442, em 6 de outubro, houve autorização formal para que o BCB pudesse fazer operações de redesconto com garantias reais ou fidejussória; (v) em 8 de outubro ampliou-se o valor dedutível de recolhimento compulsório e redução da alíquota de exigibilidades adicionais; (vi) em 13 de outubro nova ampliação do valor dedutível de recolhimento compulsório sobre depósitos a prazo; (vii) em 13 de outubro, liberação de compulsórios dos bancos que acessarem o redesconto até que a operação se concretize; (viii) em 14 de outubro, o BCB reduziu a alíquota do compulsório sobre depósitos à vista e aumento da alíquota do direcionamento obrigatório ao crédito rural; (ix) em 15 de outubro

\footnotetext{
${ }^{29}$ Representa 2,4\% do total de quase US\$ 205 bilhões de reservas em 5/11/2008.

${ }^{30}$ Linha semelhante havia de swap de moedas foram negociadas pelo FED com 10 autoridades monetárias: Europa, Inglaterra, Suíça, Japão, Austrália, Nova Zelândia, Canadá, Suécia, Noruega e Dinamarca. Entre os emergentes, além do Brasil, só México, Cingapura e Coréia estabeleceram acordo semelhante.
} 
ampliou-se os tipos de ativos elegíveis para compra pelos bancos com abatimento do compulsório.

Estas medidas têm por objetivos de política monetária: (i) prover liquidez para bancos pequenos e médios, inclusive os bancos das montadoras; (ii) destravar o crédito interbancário e para a sociedade em geral; (iii) aprimorar do mecanismo do redesconto, facilidade pela qual o BC é emprestador de última instância.

Para cumprir estes objetivos, $R \$ 47$ bilhões serão destinados a prover liquidez para $\mathrm{O}$ sistema bancário, sendo que deste montante $\mathrm{R} \$ 29,5$ bilhões disponibilizados para os bancos pequenos e médios; R $\$ 6$ bilhões para compras de dólares com compromisso de venda simultânea e R $\$ 5$ bilhões como recursos adicionais para o crédito agrícola.

Quanto à política monetária via depósitos compulsórios houve, portanto, ampliação da dedução, adiamento e/ou redução de alíquota sobre várias modalidades de compulsório. Houve anúncio para liberação integral de compulsórios sobre depósitos a prazo interfinanceiros e uma redução adicional de $\mathrm{R} \$ 100$ bilhões; redução do compulsório sobre depósitos a prazo de adquirente de carteiras de ativos de outra instituição; liberação de compulsório para antecipação da contribuição ao Fundo Garantidor de Crédito (FGC) e 70\% do recolhimento compulsório sobre depósitos a prazo passou a ser efetuado em espécie.

Quanto às medidas de retomada de crédito observou-se: (i) pela MP 442, de 06 de outubro, autorização formal para que o BCB possa fazer operações de empréstimo; (ii) pela MP 443, de 21 de outubro, autorização para que o Banco do Brasil e Caixa Econômica Federal adquiram participação acionária em outras instituições; (iii) aumento da exigibilidade de aplicação de depósitos à vista e da poupança rural no crédito rural; (iv) permissão para que o financiamento de capital de giro seja considerado como financiamento habitacional no cálculo da exigibilidade sobre depósitos de poupança.

Quanto ao financiamento à agricultura as medidas tomadas foram: (i) antecipação de desembolsos pelo Banco do Brasil; (ii) recursos adicionais de $\mathrm{R} \$ 5$ bilhões, vindos de vários fundos; (iii) aumento do crédito direcionado (exigibilidade) com compulsório de $\mathrm{R} \$ 5,5$ bilhões; (iv) aumento da poupança rural de $65 \%$ para $70 \%$ (R $\$ 2,5$ bilhões); (v) permissão para financiamento indireto de produtores via compra de CPR de agroindústrias e tradings; (vi) garantia de preço mínimo para safra de 2009; (vii) aquisição de produtos pelo governo para formar estoques e elevar preços, (viii) subvenção aos produtores, ou seja, pagamento da diferença entre preços de mercado e preço mínimo; (ix) créditos para a comercialização. 
Para o setor de construção civil as seguintes medidas foram tomadas: (i) linha de capital de giro de R\$ 3 bilhões, pela Caixa Econômica Federal, com recursos da poupança habitacional; (ii) permissão para utilizar até $5 \%$, nas operações de capital de giro, do limite de 65\% dos depósitos de poupança que são direcionados ao financiamento de habitação pelo SBPE. No setor automobilístico e motocicletas, o aumento do crédito foi anunciado, via Banco do Brasil, na ordem de $\mathrm{R} \$ 4$ bilhões.

Por fim, na área de política fiscal, observou-se a postergação da data dos pagamentos: o IPI, do dia 15 para o dia 25; PIS/COFINS, do dia 20 para o dia 25; IR Retido Fonte; do dia 10 para dia 20 e Contribuição da Previdência, do dia 10 para o dia 20.

\section{RESULTADOS OBSERVADOS NO CURTO PRAZO E CONSIDERAÇÕES}

Como resultados da política monetária e cambial no curtíssimo prazo, observam-se: (i) o risco de deterioração do quadro inflacionário está centrado no comportamento do crédito bancário; (ii) as operações no mercado cambial, após vendas de moeda estrangeira estão ajudando a diminuir a volatilidade, mas a moeda nacional ainda está pressionada a se depreciar; (iii) o leilão de dólares, vistos após setembro, foi direcionado para o financiamento de ACCs e ampliação do PROEX, regularizando de forma gradual a oferta de crédito às exportações; (iv) no curto prazo as reservas brasileiras foram pouco afetadas e não estão sendo comprometidas (caíram 2,4\%) sem contar o acordo de R $\$ 30$ bilhões de swap de moeda com o FED; (v) o risco de inflação permanece, ainda pela forte demanda interna e depreciação do real; (vi) caso os bancos não voltem a ter a confiança em empréstimos, mesmo após todas estas medidas tomadas pelo $\mathrm{BCB}$, medidas de política monetária graduais expansionistas, como a inclusão de um corte nos juros, ainda este ano, poderiam contribuir para melhorar a liquidez da economia. Por outro lado, um corte na taxa de juros para aumentar a liquidez, aumenta as expectativas de inflação para 2009, mesmo com a expectativa de queda do crescimento do PIB.

\section{REFERÊNCIAS}

BANCO CENTRAL DO BRASIL. Comitê de Política Monetária. Brasília. Ata da 138 reunião, 2008a. Disponível em: <http://www.bcb.gov.br/?COPOM138>. Acesso em $17 / 12 / 2008$.

BANCO CENTRAL DO BRASIL. Comitê de Política Monetária. Relatório de inflação. Brasília, 2008b. Disponível em: < http://www.bcb.gov.br/htms/relinf/port/2008/09/ ri200809P.pdf $>$. Acesso em 17/12/2008. 
MANTEGA, G. A crise internacional e os desafios para o Brasil. In: APRESENTAÇÃO NA REUNIÃO DO CONSELHO POLÍTICO, 2008a. Disponível em: $<$ http://www.fazenda.gov.br/portugues/releases/2008/outubro/061008_conselho_pol.pdf $>$. Acesso em 17/12/2008.

MANTEGA, G. Atravessando a turbulência. In: REUNIÃO DO CONSELHO DE DESENVOLVIMENTO ECONÔMICO E SOCIAL, 2008b. Disponível em: <http://www.fazenda.gov.br/portugues/documentos/2008/novembro/a061108.pdf>. Acesso em 17/12/2008.

MEIRELLES, H. de C. A crise financeira global e o Brasil. In: APRESENTAÇÃO À COMISSÃO DE ASSUNTOS ECONÔMICOS DO SENADO FEDERAL, 2008a. Disponível em: <http://www4.bcb.gov.br/pec/appron/Apres/A\%20Crise \%20Financeira $\% 20$ Global $\% 20 \mathrm{e} \% 20 \mathrm{o} \% 20$ Brasil.pdf $>$. Acesso em 17/12/2008.

MEIRELLES, H de C. Atuação do Banco Central frente à crise global. In: REUNIÃO DO CONSELHO DE DESENVOLVIMENTO ECONÔMICO E SOCIAL, 2008b. Disponível em: <http://www4.bcb.gov.br/pec/ApPron/Apres/CDES_06112008.pdf>. Acesso em 17/12/2008. 